\title{
Genistein inhibits placental choriocarcinoma cell line JAR invasion through ER//MTA3/Snail/E-cadherin pathway
}

\author{
XIAOXIA LIU ${ }^{1}$, XIAOBO LI ${ }^{2}$, LIANHUA YIN ${ }^{2}$, JINGXIN DING ${ }^{1}$, HONGYAN JIN $^{1}$ and YOUJI FENG ${ }^{1}$ \\ ${ }^{1}$ The Obstetrics and Gynecology Hospital, Fudan University, Shanghai 200090; ${ }^{2}$ Department of Physiology \\ and Pathophysiology, Fudan University Shanghai Medical College, Shanghai 200032, P.R. China
}

Received October 25, 2010; Accepted May 24, 2011

DOI: $10.3892 / \mathrm{ol} .2011 .338$

\begin{abstract}
Genistein, the most abundant phytoestrogen in soybeans, may bind to estrogen receptors and perform anticancer activities. Choriocarcinoma is a malignant, trophoblastic and aggressive cancer of the placenta. Few studies are currently available concerning the effects of genistein on choriocarcinoma. In the present study, we investigated the effect of genistein on the invasive potential of the choriocarcinoma cell line JAR and its underlying mechanism. Our data revealed that genistein inhibited JAR cell invasion in a dose-dependent manner by a matrigel invasion assay. Moreover, genistein was found to have decreased the metastasis-associated gene MTA3 mRNA level, increased the transcriptional suppressor Snail mRNA level and upregulated the protein expression of the cell-cell adhesion molecule E-cadherin by real-time RT-PCR and Western blot analysis, respectively. ER $\beta$ siRNA was used to knock down ER $\beta$ expression in JAR cells. In the ER $\beta$-knockdown JAR cells, genistein failed to inhibit JAR cell invasion. The effects of genistein on MTA3, Snail and E-cadherin expression were also eradicated following ER $\beta$ siRNA transfection. These results demonstrated that genistein triggered the MTA3/Snail/E-cadherin regulatory pathway by binding with ER $\beta$, thereby inhibiting JAR cell invasion. In conclusion, our findings have significant implications for the prevention and therapy of choriocarcinoma.
\end{abstract}

Correspondence to: Dr Youji Feng, The Obstetrics and Gynecology Hospital, Fudan University, M.D. 128, Shenyang Road, Yangpu, Shanghai 200090, P.R. China

E-mail: fengyj4806@soho.com

Abbreviations: MTA3, metastasis-associated protein 3; PCR, polymerase chain reaction; RT-PCR, reverse transcription-PCR; ER, estrogen receptor; HCG, human chorionic gonadotropin; FBS, fetal bovine serum; EDTA, ethylene diamine tetraacetie acid; HEPES, 4-(2-Hydroxyethyl)-1-piperazineethanesulfonic acid; FITC, fluorescein isothiocyanate; GAPDH, glyceraldehyde-3-phosphate dehydrogenase; BCA, bicinchoninic acid; siRNA, small interfering RNA; PBS, phosphate-buffered saline

Key words: genistein, invasion, choriocarcinoma, ER $\beta$, MTA3, Snail, E-cadherin

\section{Introduction}

Choriocarcinoma is a malignant, trophoblastic and aggressive cancer of the placenta. Human placenta is an efficient endocrine organ producing large amounts of human chorionic gonadotropin, steroid hormones, cytokines, and growth factors. After the first trimester, the placenta becomes the major site of estradiol production. Estrogens, generated by paracrine and/or autocrine mechanisms, may play a significant role in mitogenic and/or developmental actions on trophoblast cells (1). Through genomic and/or non-genomic signaling pathways, estrogen exerts its biological responses by binding to estrogen receptors, which are members of the nuclear receptor superfamily. $\mathrm{ER} \alpha$ and $\mathrm{ER} \beta$ are two isoforms that have been identified thus far. Both monomeric forms of each receptor subtype are approximately $60 \mathrm{kDa}$ and both subtypes bind estradiol-17 with high affinity but differ in DNA-binding affinity. These two ER subtypes are capable of mediating different functions depending on the nature of bound ligands, post-translational modifications, cofactor interactions and promoter response elements $(2,3)$. The expression and functions of the two ER subtypes in placenta were previously confirmed. ER $\alpha$ and ER $\beta$ mRNA levels increased from the first to the second trimester and then decreased until normal term delivery in placenta $(4,5)$.

Genistein, a well-known isoflavone, is found in a number of plants, fruits and vegetables. Since isoflavones possess a phenolic ring system similar to that of estrogens they are able to bind to estrogen receptors in humans. Genistein may bind to both $\mathrm{ER} \alpha$ and $\mathrm{ER} \beta$, but with an even higher affinity for $\mathrm{ER} \beta$ than steroidal estrogens (6). Recent studies have shown that genistein is a potent inhibitor of tyrosine kinase, which is involved in almost all cell growth and proliferation signal cascades. Moderate doses of genistein have been found to have inhibitory effects on cancers of the prostate, cervix, brain, breast and colon $(7,8)$. However, few studies are currently available regarding the effects of genistein on choriocarcinoma.

E-cadherin is a cell-cell adhesion molecule, which is thought to play a significant role in trophoblastic differentiation and remodeling during gestation. In extravillous trophoblasts and choriocarcinomas, the highly invasive behavior is associated with a reduced expression of E-cadherin $(9,10)$. Both the functional disruption of E-cadherin using monoclonal antibodies and loss of E-cadherin expression are capable of eliciting the acquisition of invasive growth. 
Table I. Primer pairs used to amplify PCR products.

\begin{tabular}{lcc}
\hline Gene & \multicolumn{1}{c}{ Primer sense } & Primer antisense \\
\hline MTA3 & TGTAAGATGCTTTTAAATTCTTAACC & GTACACAAGAACTTATGTTTATTGC \\
Snail & AATCGGAAGCCTAACTACAGCG & GTCCCAGATGAGCATTGGCA \\
ER $\beta$ & TCACATCTGTATGCGGAACC & CGTAACACTTCCGAAGTCGG \\
GAPDH & CAATGACCCCTTCATTGACC & TTGATTTTGGAGGGATCTCG \\
\hline
\end{tabular}

As a key component of an estrogen-dependent pathway regulating growth and differentiation, MTA3 is ubiquitously expressed and suppresses estrogen receptor element-dependent gene transcription activity. A high expression of MTA3 is associated with invasiveness (11).

Zinc-finger transcription factor Snail is known to be involved in the triggering of the epithelial-mesenchymal transition in the precursors of the mesoderm and neural crest (12). Findings of previous studies showed that Snail is not only capable of directly suppressing E-cadherin gene transcription by binding to the E-box on the E-cadherin promoter, but also accelerates cancer invasion in various types of carcinomas (13). Snail has been reported to be a direct regulatory target of MTA3 action, and MTA3 may regulate the Snail and E-cadherin expression levels in tumor cells. In the estrogen receptor-positive cells, estrogen indirectly upregulates MTA3, which suppresses Snail expression, which in turn suppresses E-cadherin expression.

In the present study, we investigated the effects of genistein on the invasive potential of the human placental choriocarcinoma cell line JAR. To explore its underlying mechanism, we examined whether the ER $\beta / M T A 3 /$ Snail/E-cadherin signaling pathway is involved in the inhibitory effects of genistein on JAR cell invasion.

\section{Materials and methods}

Materials. Culture media, reagents and SuperScript ${ }^{\mathrm{TM}}$ III first strand synthesis system for RT-PCR were purchased from Invitrogen (Carlsbad, CA, USA). SV total RNA isolation kit was purchased from Promega (Madison, WI, USA) and SYBR ${ }^{\circledR}$ Green real-time PCR Master Mix from Toyobo Company (Osaka, Japan). Genistein was purchased from Sigma-Aldrich Chemical Co. (St. Louis, MO, USA). Primary antibodies against E-cadherin, $\beta$-actin and secondary antibodies against rabbit and mouse IgG were purchased from SantaCruz Biotechnology, Inc. (Santa Cruz, CA, USA). Other reagents were purchased from Sigma-Aldrich Chemical Co. unless otherwise mentioned.

Cell culture. The human choriocarcinoma JAR cell line, ATCC HTB-144, was routinely maintained in a humidified atmosphere with $5 \% \mathrm{CO}_{2}$ in RPMI-1640 containing $1 \mathrm{mM}$ sodium pyruvate, $10 \mathrm{mM}$ HEPES, $2 \mathrm{mM}$ L-glutamine and $4.5 \mathrm{~g} / \mathrm{l}$ glucose. The cell line was then supplemented with $10 \%$ (v/v) heat-inactivated fetal bovine serum (FBS), $100 \mathrm{IU} / \mathrm{ml}$ penicillin and $100 \mathrm{mg} / \mathrm{ml}$ streptomycin.

Transfection of JAR cells with ER $\beta$ siRNA. FITC-labeled siRNA against ER $\beta$ and control siRNA were synthesized by Gene Pharma (Shanghai, China). JAR cells were transfected with 40 pmol ER $\beta$ or control siRNA using lipofectamine 2000
(Invitrogen) according to the manufacturer's instructions. After $24 \mathrm{~h}$, the transfection efficacy was measured by flow cytometry.

Matrigel invasion assay. Achemoinvasion assay was performed as previously reported with some modifications (14). Cell invasiveness was evaluated using a BD BioCoat ${ }^{\mathrm{TM}}$ Matrigel $^{\mathrm{TM}}$ Invasion Chamber (BD Biosciences). Briefly, JAR cells treated with or without ER $\beta$ siRNA for $24 \mathrm{~h}$ were digested with $0.125 \%$ trypsin-EDTA and re-suspended in serum-free RPMI1640. Polycarbonate filters (8-mm pore size) were coated with $20 \mu 1$ of diluted matrigel (1:2 in RPMI-1640) on the upper side. The matrigel on the filters was reconstituted with serum-free RPMI- 1640 at $37^{\circ} \mathrm{C}$ for $30 \mathrm{~min}$ prior to use. Following reconstitution, the medium was carefully removed. Medium $(0.8 \mathrm{ml})$ containing 10\% FBS (chemoattractant) was then added to each well of the plate and $200 \mu 1$ of cell suspension $\left(1 \times 10^{5}\right.$ cells) was immediately added to the matrigel-coated inserts. The cells were incubated with $0,10,25,50$ or $100 \mu \mathrm{M}$ genistein for $72 \mathrm{~h}$. Following incubation, the medium was removed and cells on both sides of the membrane were fixed in methanol for $5 \mathrm{~min}$ and then stained with hematoxylin. The non-invasive cells were removed with a cotton bud. The number of invasive cells was then counted in 5 random fields of the insert under a light microscope.

$R T$-PCR and quantitative real-time RT-PCR. JAR cells treated with or without ER $\beta$ siRNA were starved in serum-free medium for $24 \mathrm{~h}$, followed by the addition of $25 \mu \mathrm{M}$ genistein for the indicated time. Total RNA was extracted according to the manufacturer's instructions. Total RNA $(2 \mu \mathrm{g})$ was reverse transcribed and amplified. The relative mRNA level was measured by real-time reverse transcription-polymerase chain reaction (RT-PCR) using SYBR-Green real-time RT-PCR mastermix (Toyobo, Osaka, Japan). GAPDH was used as an internal standard. To confirm the deficiency of ER $\beta$ in the ER $\beta$ siRNA-transfected JAR cells, ER $\beta$ and GAPDH were amplified by PCR. The PCR fragments were visualized on a $2 \%$ agarose gel containing $5 \mathrm{mg} / \mathrm{ml}$ ethidium bromide. Table I shows the specific primer pairs for MTA3, Snail, GAPDH and ER $\beta$.

Western blot analysis. JAR cells treated with or without ER $\beta$ siRNA were incubated with $10,25,50$ or $100 \mu \mathrm{M}$ genistein for $72 \mathrm{~h}$. Total cell lysates from treated cells were harvested in RIPA lysis buffer. Protein concentrations were determined using the bicinchoninic acid method. Total cell lysates (30 $\mu \mathrm{g})$ were separated by sodium dodecyl sulfate polyacrylamide gel electrophoresis (SDS-PAGE) to detect the E-cadherin protein expression using $\beta$-actin as a loading control. Following SDS-PAGE, proteins were electrophoretically transferred to 

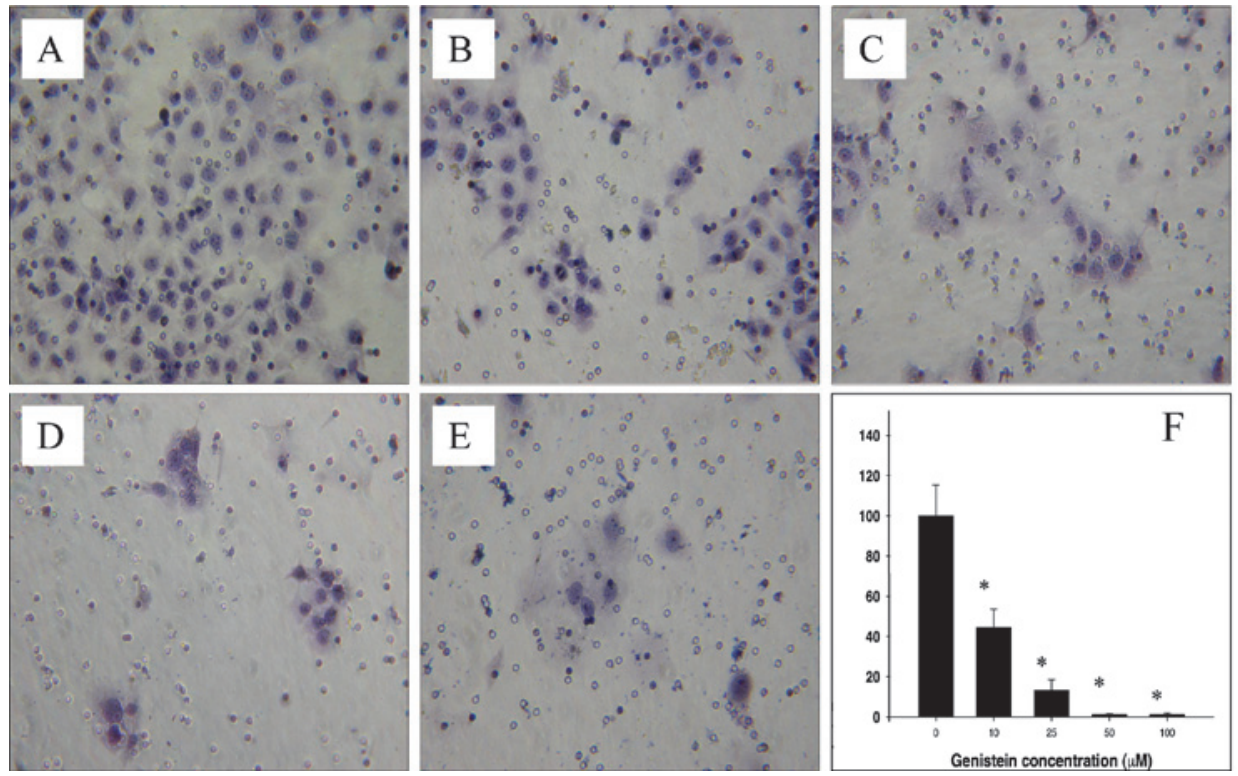

Figure 1. Inhibition of invasive potential of JAR cells by genistein. JAR cells treated in the absence or presence of genistein were subject to matrigel chamber assays as described in Materials and methods. After $72 \mathrm{~h}$, the number of cells invading through the matrigel and traversing the membrane were counted after staining with hematoxylin. Fields (5 per sample) were counted and averaged. (A-E) The representative fields of invaded cells treated with $0,10,25,50$ or $100 \mu \mathrm{M}$ genistein, respectively, are shown. (F) The inhibition of invasive potential of JAR cells is shown, indicated as the mean of results obtained from three independent experiments $\pm \mathrm{SD}$. ${ }^{*} \mathrm{P}<0.05$ vs. the non-genistein-treated group.

PVDF membranes (Millipore, Billerica, MA, USA). The membranes were then blocked at room temperature for $2 \mathrm{~h}$ in blocking buffer (PBS, pH 7.4,0.1\% Tween, 5\% non-fat dry milk). Proteins were then incubated at $4^{\circ} \mathrm{C}$ overnight with a mouse monoclonal IgG against human E-cadherin. After washing with PBS, pH 7.4, containing $0.05 \%$ Tween-20, goat anti-mouse IgG-horse-radish peroxidase conjugate, 1:2000, in washing solution was added and incubated for $1 \mathrm{~h}$ at room temperature. Protein bands were detected using the Perkin-Elmer ECL Kit. The band densities were quantified by densitometry using GIS software (Bio-Tanon, Shanghai, China).

Statistical analysis. Data were reported as mean \pm standard deviation and subjected to one-way analysis of variance. $\mathrm{P}<0.05$ was considered to be statistically significant.

\section{Results}

Inhibition of invasive potential of JAR cells by genistein. To evaluate the invasive potential of JAR by genistein, a matrigel invasion assay was performed. Over a period of 3 days, a strong suppression of JAR invasion was observed. As shown in Fig. 1, compared with the control group, the invasive potential of JAR cells treated with $10,25,50$ or $100 \mu \mathrm{M}$ genistein decreased by approximately 55.6\% $(\mathrm{P}<0.05), 86.7 \%(\mathrm{P}<0.05)$, 98.9\% $(\mathrm{P}<0.05)$ and $98.9 \%(\mathrm{P}<0.05)$, respectively.

Effects of genistein on MTA3, Snail and E-cadherin expression in JAR cells. MTA3, Snail and E-cadherin are components of a pathway correlated with invasion and metastasis. To determine the hypothesis that genistein inhibits JAR cell invasion through this pathway, the protein levels of E-cadherin were detected by Western blot analysis as shown in Fig. 2A and B. Compared with the control group, E-cadherin protein levels were increased by 2.7-, 3.1-, 3.2- and 2.6-fold after incubation with $10,25,50$ or $100 \mu \mathrm{M}$ genistein, respectively, for $72 \mathrm{~h}$ in JAR cells. To investigate whether MTA3 and Snail were involved in the upregulation of E-cadherin by genistein, the mRNA levels of MTA3 and Snail in JAR cells treated with $25 \mu \mathrm{M}$ genistein for $0,1,2,4,8$ or $12 \mathrm{~h}$ were measured using a real-time RT-PCR assay. Consequently, the addition of genistein for 1,2, 4 or $8 \mathrm{~h}$ markedly increased the mRNA expression of MTA3 $(\mathrm{P}<0.05)$. After $12 \mathrm{~h}$ of treatment with genistein, the MTA3 mRNA level was found to be lower than that of the control level. By contrast, the Snail mRNA level was downregulated by genistein after $4 \mathrm{~h}$ of treatment, and reached the control level at $8 \mathrm{~h}$. Thus, genistein may inhibit JAR cell invasion by suppressing E-cadherin expression, which is correlated with the upregulation of the MTA3 level and downregulation of the Snail level.

Effect of genistein on the invasive potential of ER $\beta$-knockdown $J A R$ cells. As previously indicated, genistein inhibited JAR cell invasion in a dose-dependent manner. In their study, Manas et al demonstrated that genistein possesses a high affinity for ER $\beta$ ligand (15). To elucidate whether or not the genistein-inhibited invasive potential was mediated by ER $\beta$, we investigated the effect of genistein on the invasive potential of ER $\beta$-knockdown JAR cells. ER $\beta$ siRNA was used to knock down the ER $\beta$ expression. JAR cells were transfected with ER $\beta$ or control siRNA by lipofectamine 2000. Results of the flow cytometry assay showed the transfection efficacy to be approximately $90 \%$. After 24 and $48 \mathrm{~h}$ of transfection the ER $\beta$ protein level was markedly decreased in ER $\beta$ siRNAtransfected cells by RT-PCR analysis compared with control siRNA (Fig. 3). As shown in Fig. 4A, in the absence of genistein treatment, ER $\beta$ siRNA-treated JAR cells exhibited decreased invasive ability compared to the control siRNA- 
A
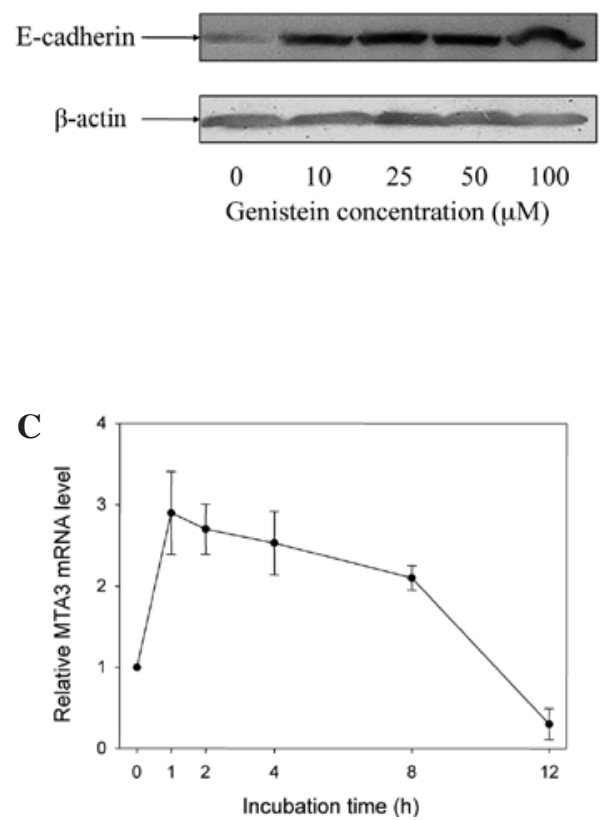

B

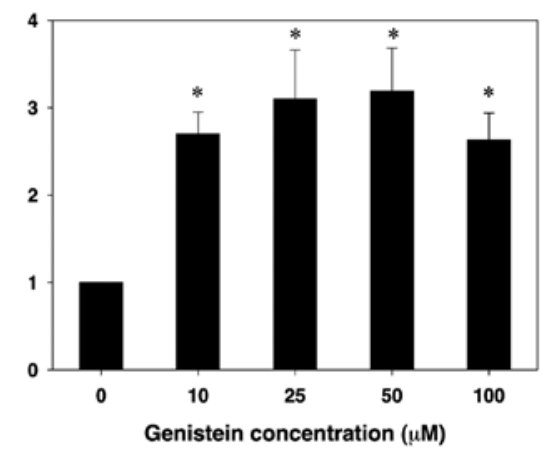

D

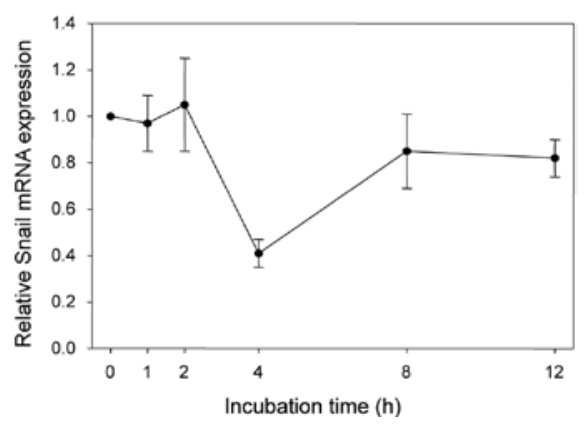

Figure 2. Effect of genistein on MTA3, Snail and E-cadherin expression in JAR cells. (A and B) JAR cells were incubated with $0,10,25,50$ or $100 \mu \mathrm{M}$ genistein for $72 \mathrm{~h}$ and harvested. E-cadherin expression in the total cell lysates was analyzed by Western blot analysis. $\beta$-actin was used as the protein loading control. JAR cells were incubated with $25 \mu \mathrm{M}$ genistein for $0,1,2,4,8$ and $12 \mathrm{~h}$ and harvested for total RNA extraction. (C) MTA3 mRNA expression was analyzed by real-time RT-PCR and normalized to GAPDH level. (D) Snail mRNA expression was analyzed by real-time RT-PCR and normalized to the GAPDH level. The data are the mean of results obtained from three independent experiments \pm SD. ${ }^{*}<0.05$ vs. the non-genistein-treated group.

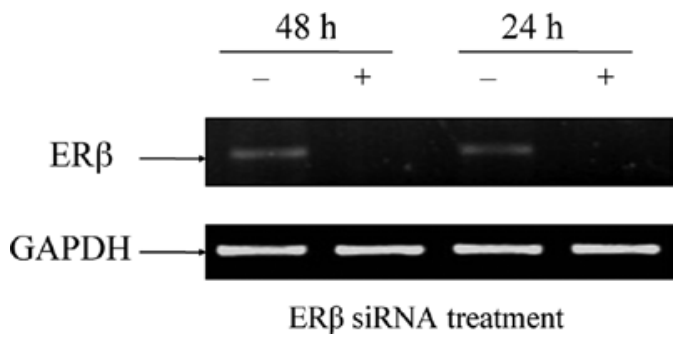

Figure 3. ER $\beta$ siRNA knocks down ER $\beta$ expression in JAR cells. JAR cells were transfected with ER $\beta$ or control siRNA by lipofectamine 2000. ER $\beta$ mRNA levels after siRNA transfection for 24 and $48 \mathrm{~h}$ were detected by RT-PCR and visualized by agarose gel.

treated cells $(\mathrm{P}<0.05)$, suggesting that $\mathrm{ER} \beta$ was crucial for the invasiveness of JAR cells. Fig. 4B shows the relative invasive potentials of the ER $\beta$ siRNA- and control siRNA-treated JAR cells treated with genistein, which were normalized to the nongenistein-treated groups. The invasive abilities of the control siRNA-treated JAR cells were decreased to 44.4 and $13.3 \%$ by 10 and $25 \mu \mathrm{M}$ genistein, respectively, whereas no alteration of invasive potential was observed in ER $\beta$ siRNA-treated JAR cells. Following treatment with 50 and $100 \mu \mathrm{M}$ genistein, the invasive potential of ER $\beta$ siRNA-treated cells was found to be 31.3 and $19.3 \%$, respectively, which was markedly higher than that of the control siRNA-treated JAR cells. These data suggest that inhibition of the invasive potential of JAR cells by low concentrations of genistein was mediated by ER $\beta$. High concentrations of genistein suppressed JAR cell invasion partially, though not completely, through ER $\beta$.
$\mathbf{A}$

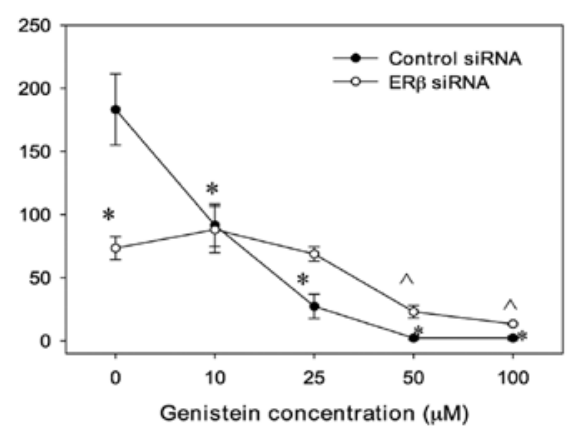

B

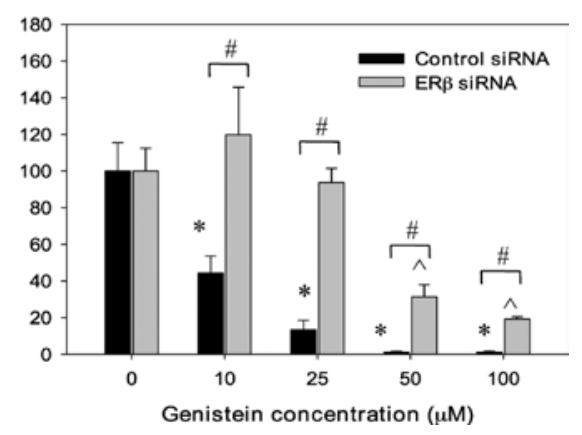

Figure 4. Effect of genistein on the invasive potential of ER $\beta$-knockdown JAR cells. Following $24 \mathrm{~h}$ of transfection with ER $\beta$ or control siRNA, JAR cells were subject to matrigel invasion assay in the presence of $0,10,25,50$ or $100 \mu \mathrm{M}$ genistein for $72 \mathrm{~h}$. (A) The number of invaded cells as indicated treatment per field were counted after staining with hematoxylin. Fields (5 per sample) were counted and averaged. (B) The relative invasive potentials normalized to non-genistein groups are shown. The data are the mean of results obtained from three independent experiments \pm SD. ${ }^{*} \mathrm{P}<0.05$ vs. non-genistein-treated JAR cells with control siRNA. ${ }^{\wedge} \mathrm{P}<0.05$ vs. non-genistein-treated JAR cells with ER $\beta$ siRNA. ${ }^{*} \mathrm{P}<0.05$ vs. control siRNA-treated JAR cells with corresponding concentrations of genistein. 
A

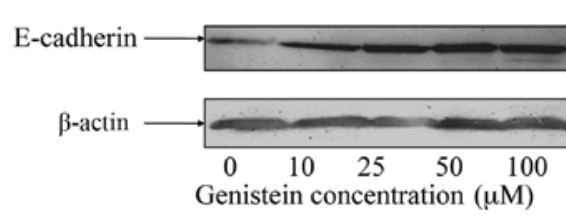

ER $\beta$ siRNAs treatment

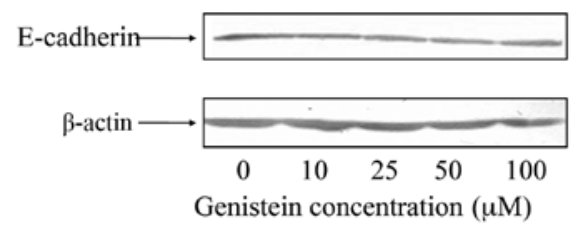

C

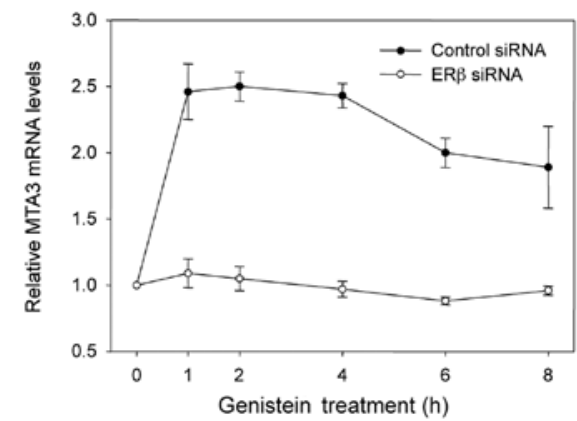

B

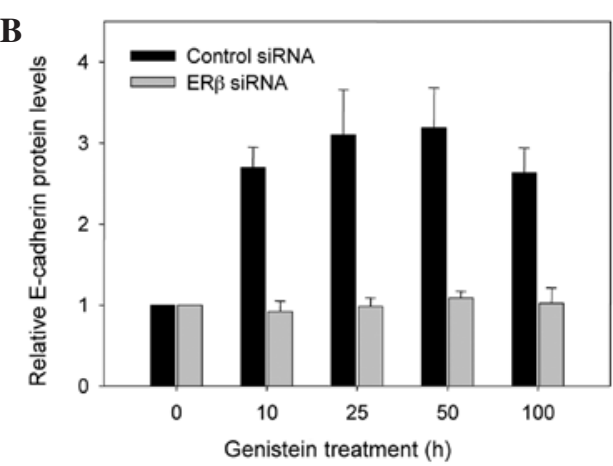

D

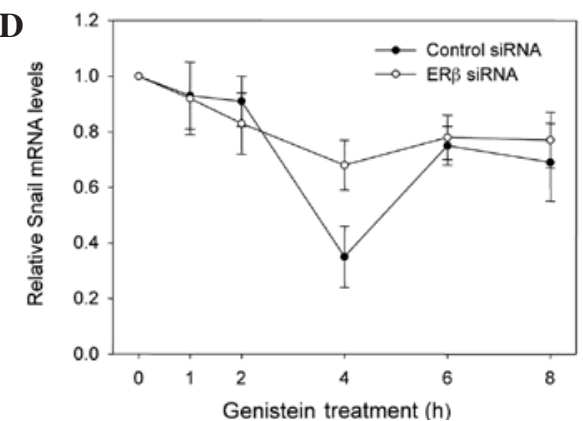

Figure 5. Effect of genistein on MTA3, Snail and E-cadherin expression in ER $\beta$-knockdown JAR cells. (A and B) Following 24 h of transfection with ER $\beta$ or control siRNA, JAR cells were incubated with $0,10,25,50$ or $100 \mu \mathrm{M}$ genistein for $72 \mathrm{~h}$ and harvested to determine the protein levels of E-cadherin using Western blot analysis. Following $24 \mathrm{~h}$ of transfection with siRNA or control siRNA, JAR cells were incubated with $25 \mu \mathrm{M}$ genistein for $1,2,4,6$ and 8 h, followed by total RNA purification. (C) MTA3 and (D) ER $\beta$ Snail mRNA levels were analyzed by real-time RT-PCR and normalized to the GAPDH levels. The data are as the mean of results obtained from three independent experiments $\pm \mathrm{SD}$. $\mathrm{P}<0.05$ vs. non-genistein-treated JAR cells with control siRNA. ${ }^{\#} \mathrm{P}<0.05$ vs. control siRNA-treated JAR cells with corresponding concentrations of genistein.

Effect of genistein on MTA3, Snail and E-cadherin expression in ER $\beta$-knockdown JAR cells. We demonstrated that antiinvasion activity by genistein may occur through the MTA3/ Snail/E-cadherin pathway in JAR cells and that genistein inhibited JAR cell invasion by binding with ER $\beta$. However, MTA3, Snail and E-cadherin are components of a pathway downstream of ER. To investigate whether the effect of genistein on MTA3, Snail and E-cadherin expression in JAR cells was mediated by ER $\beta$, the effect of genistein on MTA3, Snail and E-cadherin levels was investigated in ER $\beta$-knockdown JAR cells. As shown in Fig. 5A, the dose-dependent upregulation of MTA3 mRNA levels by genistein was eliminated by ER $\beta$ siRNA treatment $(\mathrm{P}<0.05)$. Fig. $5 \mathrm{~B}$ shows that decrease of the Snail mRNA level at $4 \mathrm{~h}$ incubation with genistein was eliminated by ER $\beta$ siRNA treatment $(\mathrm{P}<0.05)$. Following treatment with ER $\beta$ siRNA, $25 \mu \mathrm{M}$ genistein was added for $72 \mathrm{~h}$ and cells were collected for Western blot analysis. In contrast to the group treated with control siRNA, genistein failed to induce E-cadherin upregulation (Fig. 5C and D), coinciding with the failed inhibition of invasion. These results demonstrate that genistein triggered the MTA3/Snail/E-cadherin regulatory pathway by binding with ER $\beta$ and then inhibited JAR cell invasion.

\section{Discussion}

The present study has shown a novel observation that genistein may inhibit the invasion of choriocarcinoma and its underlying mechanism. Using the human placental choriocarcinoma cell line JAR in vitro, our findings showed that genistein i) inhibited the invasive potential of JAR cells in a dose-dependent manner; ii) increased the E-cadherin protein expression, increased MTA3 mRNA levels, and suppressed Snail mRNA levels; and iii) elicited the above process through ER $\beta$-mediated transduction pathways. Thus, our findings have significant implications for the prevention and therapy for choriocarcinoma.

Since it was reported that Asians have significantly lower risk of breast, colon and prostate cancers than Americans (the Asian consumption of soya is approximately 20-50 times that of Americans), numerous studies on genistein have revealed it to be a potent tyrosine kinase inhibitor with a protective effect against tumors (16-18). Kousidou et al demonstrated that genistein suppresses the invasive potential of human breast cancer cells through the transcriptional regulation of metalloproteinases and their tissue inhibitors (19). Results by Huang et al revealed that genistein inhibits p38 MAP kinase activation, matrix metalloproteinase type 2 , and cell invasion in human prostate epithelial cells $(20,21)$. Lakshman et al also reported that dietary genistein inhibited the metastasis of human prostate cancer in mice (22). Our data revealed for the first time that genistein at $10-100 \mu \mathrm{M}$ significantly inhibited the invasion of the human placenta choriocarcinoma cell line JAR in a dose-dependent manner.

E-cadherin is a significant cell adhesion molecule that mediates cell-cell adhesion. Various clinical and epidemio- 
logical data have indicated that loss of E-cadherin adhesion functions is frequently involved in the development of tumor invasiveness, and the level of E-cadherin expression in a tumor correlates with tumor grading and the malignant potential of a tumor (23). Karmakar et al reported that in extravillous trophoblasts and choriocarcinomas, the highly invasive behavior was associated with a reduced E-cadherin expression (24). Batlle et al and Hajra et al demonstrated that the transcription factor Snail, expressed by fibroblasts and certain epithelial tumor cells, suppresses E-cadherin gene expression by binding directly to the E-boxes present in the proximal E-cadherin promoter $(13,25)$. In addition to these reports, Fujita et al showed that the transcription factor Snail was a direct regulatory target of MTA3 action. MTA3, a Mi-2/NuRD complex, markedly elevated Snail and E-cadherin levels (26). MTA3, Snail and E-cadherin are components of a regulatory pathway downstream of the estrogen receptor. Therefore, in the present study, we investigated whether the MTA3/Snail/E-cadherin regulatory pathway is involved in the inhibition of invasion by genistein. mRNA expression of MTA3 and Snail and the protein expression of E-cadherin was detected by real-time RT-PCR and Western blot analysis. We found that the genistein-treated JAR cells exhibited an increase of MTA3 and a decrease of Snail, resulting in the upregulation of E-cadherin expression. In other words, genistein suppressed the invasion of JAR cells through the MTA3/Snail/E-cadherin regulatory pathway.

Recent investigations have revealed that ER $\beta$ acts as a counter-partner of ER $\alpha$ through inhibition of the transactivating function of ER $\alpha$ by heterodimerization, distinct regulation on various specific promoters by ER $\alpha$ or ER $\beta$, and ER $\beta$-specific regulated genes that are probably related to its anti-proliferative properties (27). Epidemiological studies of genistein consumption indicate the possible contribution of ER $\beta$-specific signaling in breast cancer prevention (27). In their study, Cheng et al also demonstrated that the expression of ER $\beta$ in prostate cancer cells leads to an inhibition of invasion (28). The mechanisms of action of genistein include the roles of these mechanisms as weak estrogens, non-specific inhibitors of tyrosine kinase-dependent signal transduction processes and cellular antioxidants (29). Genistein binds preferentially to ER $\beta$ (15). ER $\beta$ has been shown to be expressed and to be involved in placenta $(1,5)$. In the present study, we clarified that ER $\beta$ is a mediator of genistein activity in JAR cells. Additionally, our results show that the ability of genistein to regulate E-cadherin expression was mediated by ER $\beta$ since attenuation of ER $\beta$ expression by ER $\beta$ siRNA resulted in the loss of genistein induction of E-cadherin and MTA3 levels and of genistein suppression of Snail levels. In the present study, after ER $\beta$ siRNA treatment, 10-25 $\mu \mathrm{M}$ genistein failed to inhibit JAR cell invasion completely. Moreover, 50-100 $\mu \mathrm{M}$ genistein was capable of suppressing JAR cell invasion, although at a lower inhibitory rate than in control siRNA-treated JAR cells. It is possible that higher concentrations of genistein may partially, but not exclusively, exert their activity through ER $\beta$.

In conclusion, genistein triggered the MTA3/Snail/Ecadherin regulatory pathway by binding with $E R \beta$, thus inhibiting JAR cell invasion. Our findings have significant implications for the prevention and therapy of choriocarcinoma. Genistein may therefore be a novel treatment approach for choriocarcinoma that may be combined with currently available chemotherapies.

\section{Acknowledgements}

This study was supported by the National Natural Science Foundation of China (NSFC 30800547).

\section{References}

1. Jiang SW, Lloyd RV, Jin L and Eberhardt NL: Estrogen receptor expression and growth-promoting function in human choriocarcinoma cells. DNA Cell Biol 16: 969-977, 1997.

2. Fox EM, Davis RJ and Shupnik MA: ERbeta in breast canceronlooker, passive player, or active protector? Steroids 73: 1039-1051, 2008.

3. Moggs JG and Orphanides G: Estrogen receptors: orchestrators of pleiotropic cellular responses. EMBO Rep 2: 775-781, 2001.

4. El Shalakany AH, Kamel KM, Ismail AM, Salah L, Deen Fahmy SS and El Deen AE: Estrogen and progesterone receptors and telomerase enzyme immunohistochemical detection in gestational trophoblastic tumors. Int $\mathrm{J}$ Gynecol Cancer 16: 1918-1926, 2006.

5. Fujimoto J, Nakagawa Y, Toyoki H, Sakaguchi H, Sato E and Tamaya T: Estrogen-related receptor expression in placenta throughout gestation. J Steroid Biochem Mol Biol 94: 67-69, 2005.

6. Setchell KD: Phytoestrogens: the biochemistry, physiology, and implications for human health of soy isoflavones. Am J Clin Nutr 68: 1333S-1346S, 1998.

7. Taylor CK, Levy RM, Elliott JC and Burnett BP: The effect of genistein aglycone on cancer and cancer risk: a review of in vitro, preclinical, and clinical studies. Nutr Rev 67: 398-415, 2009.

8. Szkudelska K and Nogowski L: Genistein - a dietary compound inducing hormonal and metabolic changes. J Steroid Biochem Mol Biol 105: 37-45, 2007.

9. Hohn HP, Grummer R, Bosserhoff S, Graf-Lingnau S, Reuss B, Backer $C$ and Denker HW: The role of matrix contact and of cell-cell interactions in choriocarcinoma cell differentiation. Eur J Cell Biol 69: 76-85, 1996.

10. Zhao HB, Wang C, Li RX, Tang CL, Li MQ, Du MR, Hou XF and Li DJ: E-Cadherin, as a negative regulator of invasive behavior of human trophoblast cells, is down-regulated by cyclosporin A via epidermal growth factor/extracellular signalregulated protein kinase signaling pathway. Biol Reprod 83: $370-376,2010$.

11. Toh Y and Nicolson GL: The role of the MTA family and their encoded proteins in human cancers: molecular functions and clinical implications. Clin Exp Metastasis 26: 215-227, 2009.

12. Cano A, Perez-Moreno MA, Rodrigo I, Locascio A, Blanco MJ, del Barrio MG, Portillo F and Nieto MA: The transcription factor Snail controls epithelial-mesenchymal transitions by suppressing E-cadherin expression. Nat Cell Biol 2: 76-83, 2000.

13. Batlle E, Sancho E, Franci C, Dominguez D, Monfar M, Baulida $\mathbf{J}$ and Garcia DH: The transcription factor snail is a repressor of E-cadherin gene expression in epithelial tumour cells. Nat Cell Biol 2: 84-89, 2000.

14. Hajra KM and Fearon ER: Cadherin and catenin alterations in human cancer. Genes Chromosomes Cancer 34: 255-268, 2002.

15. Manas ES, Xu ZB, Unwalla RJ and Somers WS: Understanding the selectivity of genistein for human estrogen receptor-beta using X-ray crystallography and computational methods. Structure 12: 2197-2207, 2004.

16. Barnes S: Effect of genistein on in vitro and in vivo models of cancer. J Nutr 125: 777S-783S, 1995.

17. Lamartiniere CA, Moore JB, Brown NM, Thompson R, Hardin MJ and Barnes S: Genistein suppresses mammary cancer in rats. Carcinogenesis 16: 2833-2840, 1995.

18. Messina MJ, Persky V, Setchell KD and Barnes S: Soy intake and cancer risk: a review of the in vitro and in vivo data. Nutr Cancer 21: 113-131, 1994.

19. Kousidou OC, Mitropoulou TN, Roussidis AE, Kletsas D, Theocharis AD and Karamanos NK: Genistein suppresses the invasive potential of human breast cancer cells through transcriptional regulation of metalloproteinases and their tissue inhibitors. Int J Oncol 26: 1101-1109, 2005.

20. Huang X, Chen S, Xu L, Liu Y, Deb DK, Platanias LC and Bergan RC: Genistein inhibits p38 map kinase activation, matrix metalloproteinase type 2, and cell invasion in human prostate epithelial cells. Cancer Res 65: 3470-3478, 2005. 
21. Xu L, Ding Y, Catalona WJ, Yang XJ, Anderson WF, Jovanovic B, Wellman K, Killmer J, Huang X, Scheidt KA, Montgomery RB and Bergan RC: MEK4 function, genistein treatment, and invasion of human prostate cancer cells. J Natl Cancer Inst 101: 1141-1155, 2009.

22. Lakshman M, Xu L, Ananthanarayanan V, Cooper J, Takimoto CH, Helenowski I, Pelling JC and Bergan RC: Dietary genistein inhibits metastasis of human prostate cancer in mice. Cancer Res 68: 2024-2032, 2008.

23. Shao ZM, Wu J, Shen ZZ and Barsky SH: Genistein exerts multiple suppressive effects on human breast carcinoma cells. Cancer Res 58: 4851-4857, 1998.

24. Karmakar S and Das C: Modulation of ezrin and E-cadherin expression by IL-1beta and TGF-betal in human trophoblasts. J Reprod Immunol 64: 9-29, 2004.

25. Hajra KM, Chen DY and Fearon ER: The SLUG zinc-finger protein suppresses E-cadherin in breast cancer. Cancer Res 62: 1613-1618, 2002.
26. Fujita N, Jaye DL, Kajita M, Geigerman C, Moreno CS and Wade PA: MTA3, a Mi-2/NuRD complex subunit, regulates an invasive growth pathway in breast cancer. Cell 113: 207-219, 2003.

27. Saji S, Hirose M and Toi M: Clinical significance of estrogen receptor beta in breast cancer. Cancer Chemother Pharmacol 56 (Suppl 1): 21-26, 2005.

28. Cheng J, Lee EJ, Madison LD and Lazennec G: Expression of estrogen receptor beta in prostate carcinoma cells inhibits invasion and proliferation and triggers apoptosis. FEBS Lett 566: 169-172, 2004.

29. Barnes S, Boersma B, Patel R, Kirk M, Darley-Usmar VM, $\mathrm{Kim} \mathrm{H}$ and $\mathrm{Xu} \mathrm{J}$ : Isoflavonoids and chronic disease: mechanisms of action. Biofactors 12: 209-215, 2000. 